\title{
Experimental Study on the Mining-Induced Water-Resistance Properties of Clay Aquicludes and Water Conservation Mining Practices
}

\author{
Zhenli Fan, ${ }^{1,2,3}$ Kesong Fan $\mathbb{C}^{\text {, }},{ }^{4,5,6}$ Zhiguo Liu, ${ }^{1,2,3}$ Yutong Feng, ${ }^{4,5,6}$ Hua Wei, ${ }^{4,5,6}$ \\ and Yunsen Zhou $^{7}$ \\ ${ }^{1}$ CCTEG Coal Mining Research Institute, Beijing 100013, China \\ ${ }^{2}$ Coal Mining Research Branch, China Coal Research Institute, Beijing 100013, China \\ ${ }^{3}$ Coal Mining \& Designing Department, Tiandi Science \& Technology Co., Ltd., Beijing 100013, China \\ ${ }^{4}$ College of Electronic and Electrical Engineering, Henan Normal University, Xinxiang 453007, China \\ ${ }^{5}$ Henan Key Laboratory of Optoelectronic Sensing Integrated Application, Zhengzhou, China \\ ${ }^{6}$ Academician Workstation of Electromagnetic Wave Engineering of Henan Province, Zhengzhou, China \\ ${ }^{7}$ Henan Institute of Metrology, Zhengzhou 450000, China
}

Correspondence should be addressed to Kesong Fan; 2019076@htu.edu.cn

Received 9 August 2021; Accepted 18 September 2021; Published 5 October 2021

Academic Editor: Jiangyu Wu

Copyright (c) 2021 Zhenli Fan et al. This is an open access article distributed under the Creative Commons Attribution License, which permits unrestricted use, distribution, and reproduction in any medium, provided the original work is properly cited.

\begin{abstract}
The Yushen mining area contains thin bedrock and a shallow buried coal seam, where JingLe group Hipparion clay and Lishi loess serve as a high-quality cement insulation cover. This study investigates the properties of the clay layer to determine the effect of the clay aquiclude on the mining water variation and fracture characteristics. Unloading hydraulic jack experiments were performed to test the physical and mechanical properties of the clay layer and the structure was analyzed in detail. The experimental results show that mining affects the soil cracks, leading to crack opening and subsequent bridging. The permeability coefficient of the soil layer initially increases with increased unloading and then decreases. A theoretical model is developed to determine the recovery mechanism of the clay layer water insulation based on the spatial movement of the clay. The results indicate the formation of a waterproof cover type of coal mud protection. Design methods are proposed to optimize the coal pillar size. Mining damage leads to the formation of a mud-covered bridge belt, which can be designed to appropriately reduce the protective layer thickness. The model is applied to the Hao Jialiang 2301 working face. The results provide important insight on the variation characteristics of the mining water insulation in clay layers and an important reference for accurately calculating the size parameters of waterproof protective coal pillars under mud-cap conditions to increase the upper mining limit of the working face.
\end{abstract}

\section{Introduction}

Coal resources and mines are abundant in Yulin-Shenmu (Shanxi Province, China). The mining area contains a large amount of shallow buried coal seams (<200 m depth) and thin bedrock layers $(30-50 \mathrm{~m}$ or less). The regional geological conditions are generally simple and the coal quality offers special advantages. However, high intensity mining under these conditions is not conducive for controlling water. Mining under water bodies poses unique challenges, in addition to maintaining aquifer water stability and protecting the surface ecological environment [1-5]. Cohesive soil layers above a coal seam offer good water resistance and can form a high-quality cement barrier cap that plays an important role in protecting the surface aquifer, which differs from common loose sand layers in terms of water conservation and coal mining practices.

Mining research has mostly focused on ecological water levels [6-9], rock overburden height, crack development [10-16], geological conditions, water partitioning [17, 18], 
and the application of water-coal technology $[9,19-21]$ and groundwater level monitoring networks [22]. Clay aquicludes exposed to mining deformation have received less research attention and only in terms of the engineering geological characteristics of the water-resistant layer and its physical mechanical properties. Yu tested the physical and mechanical properties of the clay layer in the Yushuwan coal mine and pointed out that the red and yellow soil layer has good water resistance and swells easily upon exposure to water [23]. Li et al. described the mining-induced variation characteristics of loess from the Lishi Formation and laterite of the Baode Formation after large-scale coal mining operations in northern Shaanxi [24], and $\mathrm{Xu}$ proposed the concept of an effective water barrier thickness [25]. Zhang et al. tested the hydrological properties of the overlying rocks in the Nalinhe area and showed that the argillite has good water stability, nonswelling, and nondisintegration properties and was not easily recovered after cracking and compression [26]. Miao et al. proposed the concept of a water barrier key layer and classified the hydrogeological structure types of the Shendong mining area [27].

The Yulin-Shenmu coal mine area is known for the occurrence JingLe group Hipparion red clay and Lishi loess that form a clay aquiclude owing to their high clay mineral contents. This causes the soil to crack to a lesser degree, which suppresses the lead water cracking [28-32] and resistance of the clay layer bridge. The waterproof effect after mining recovery remains poorly understood. A calculation method is required to optimize the waterproof and protective coal pillar size for thin bedrock and thick mud-cap drilling conditions. This paper takes the Hao Jialiang coal mine of the Yushen mining area as the engineering background and studies the isolation of the mining water clay layer based on fluid-structure coupling experiments. The results are applied to practical water conservation mining operations.

\section{Physical and Mechanical Property Tests}

Drill core samples of the Lishi loess and JingLe group Hipparion red clay were collected from the Hao Jialiang coal mine 2301 face in their original state. An MIP scanning electron microscope and X-ray powder crystal diffractometer were used to determine the composition of the clay minerals. The test results are listed in Table 1. Red loess samples with different dry densities $\left(1.5-1.9 \mathrm{~g} / \mathrm{m}^{3}\right)$ were then selected to test the physical and mechanical parameters including the soil shear strength, water dilatancy, and saturated permeability coefficient using a GDS direct shear tester, an expansion-measuring instrument, and a GDS hydraulic controller, respectively. The test results are shown in Figure 1.

The red clay of the JingLe Formation is deep red in color and the Lishi Formation loess is earthy yellow. The soil particles are relatively loose with a small particle size and good homogeneity, and both contain abundant quartz and clay minerals. The clay mineral composition is dominated by Yimeng mixed beds of mostly illite. Figure 1 shows that the maximum shear stress of the red loess sample is $450-850 \mathrm{kPa}$ under a normal stress of $100 \mathrm{kPa}$ and gradually increases with increasing dry density. The red loess sample contains more hydrophilic minerals and its swelling ability is strong when exposed to water. The maximum swelling rate varies from $4.82 \%$ to $13.73 \%$ and also gradually increases with increasing dry density. The saturated permeability coefficient of the red loess samples is relatively small $(<1 \mathrm{~d} / \mathrm{m})$, which indicates weak permeability that gradually decreases with increasing dry density. Compared with the sandy soil layer, the JingLe laterite has generally high shear strength, strong expansion, extremely weak water permeability, and good water insulation properties.

\section{Mining-Induced Fluid-Solid Coupling Experiments}

Fluid-solid coupling experiments were performed to analyze the variation characteristics of the water insulation performance, recovery of the water insulation ability, and variation of the soil permeability coefficient of the clay water insulation layer after mining damage.

3.1. Experimental Design. The experimental design is shown in Figure 2. To simplify the experimental system, a clay layer was used in the lower coal seam, and bedrock and aeolian sandstone were used in the upper layer. The coal bed mining system is modified using a hydraulic jack with only the soil viscosity identified as the research object during the test. The experimental system mainly contains a model box structure, hydraulic jack, and test bench. The hydraulic jack is placed in the experimental stage through the grooves with the casing supporting plate. The external water sources are supplied by a water pipe to directly fill to the top to fill the model casing. The model box is composed of toughened glass with dimensions of $90 \times 45 \times 45 \mathrm{~cm}$ (length $\times$ width $\times$ height). The box wall thickness is $1 \mathrm{~cm}$ and is well sealed to maintain the strong bearing capacity. The lower part has six supporting plates arranged in parallel with dimensions of $45 \times 14.7 \times 1.7 \mathrm{~cm}$. There is a $3 \mathrm{~mm}$ gap to allow a water channel between the two supporting plates. The experimental system contains six hydraulic jacks as support (labeled 1-6 from left to right in Figure 2). The hydraulic jack fuselage height is $25 \mathrm{~cm}$ and has a lift range of $0-13 \mathrm{~cm}$. The top disc has a $5.5 \mathrm{~cm}$ diameter, $11 \mathrm{~cm}$ diameter base, and maximum lifting capacity of $3.2 \mathrm{t}$, which meets the experimental requirements.

3.2. Experimental Procedure. Mining water isolation experiments were carried out on the clay samples according to the following procedure.

(1) Design of the experimental scheme. Hipparion red clay of the JingLe Formation was collected from the unmodified soil of the 2301 working face of the Hao Jialiang coal mine. Two experimental schemes were designed to compare and analyze the effect of the clay layer thickness on the mining-induced water insulation. The model dimensions for experimental 
TABLE 1: X-ray diffraction results of the soil samples.

\begin{tabular}{|c|c|c|c|c|c|c|c|}
\hline \multirow[t]{2}{*}{ Soil type } & \multicolumn{5}{|c|}{ Relative content of clay minerals (\%) } & \multicolumn{2}{|c|}{$\begin{array}{c}\text { Mixed-layer ratio } S \\
(\%)\end{array}$} \\
\hline & $I / S$ & $I$ & $K$ & $C$ & $C / S$ & $I / S$ & $C / S$ \\
\hline Yellow soil & 33 & 43 & 8 & 16 & - & 60 & - \\
\hline Red soil & 60 & 23 & 8 & 9 & - & 75 & - \\
\hline
\end{tabular}

$S$ : smectite, $I / S$ : illite mixed layer, $I$ : glimmerton, $K$ : kaolinite, $C$ : chlorite, $C / S$ : green slip layer.

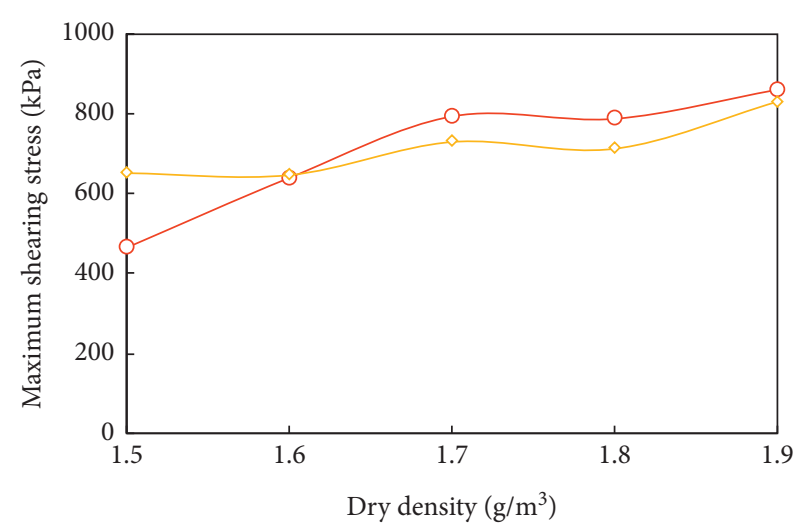

$-\circ 100 \mathrm{kPa}$ normal stress of yellow soil

$\neg-100 \mathrm{kPa}$ normal stress of red soil

(a)

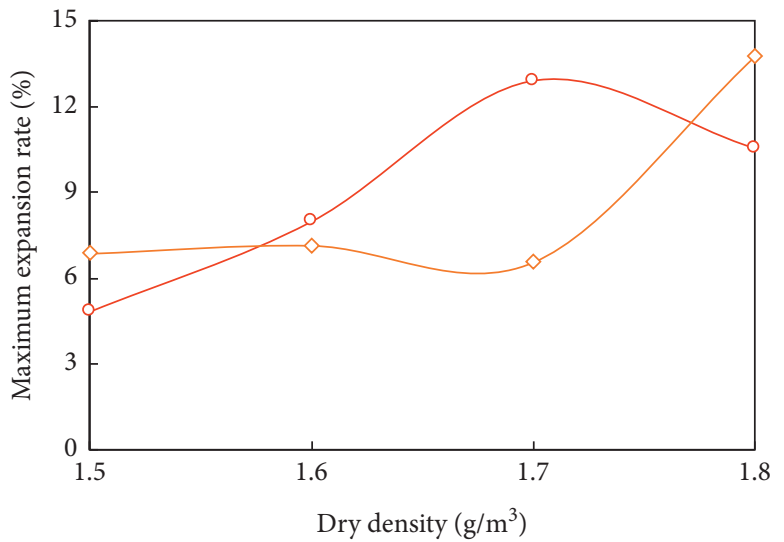

- - Red soil samples

$\leadsto$ Yellow soil samples

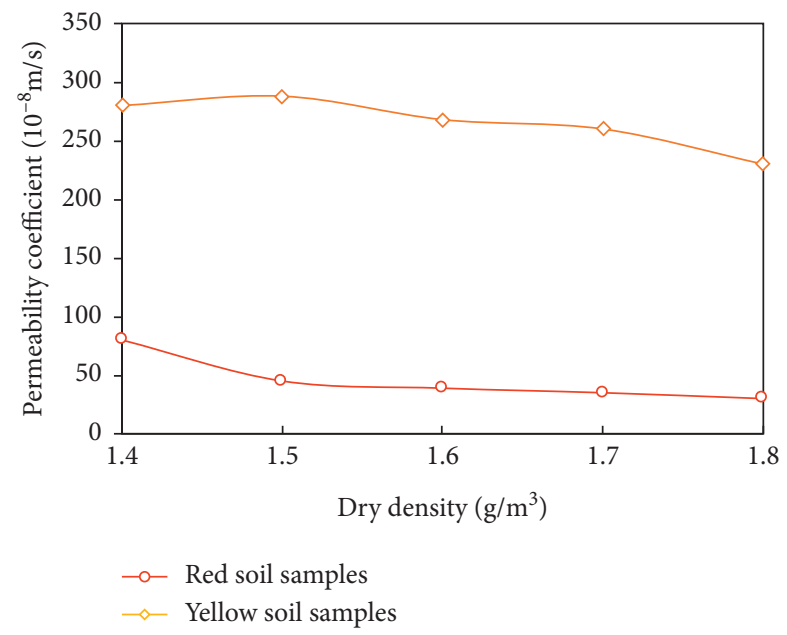

(c)

Figure 1: Physical and mechanical properties test results. Distribution of the (a) shear stress, (b) expansion rate, and (c) permeability coefficient as a function of dry density.

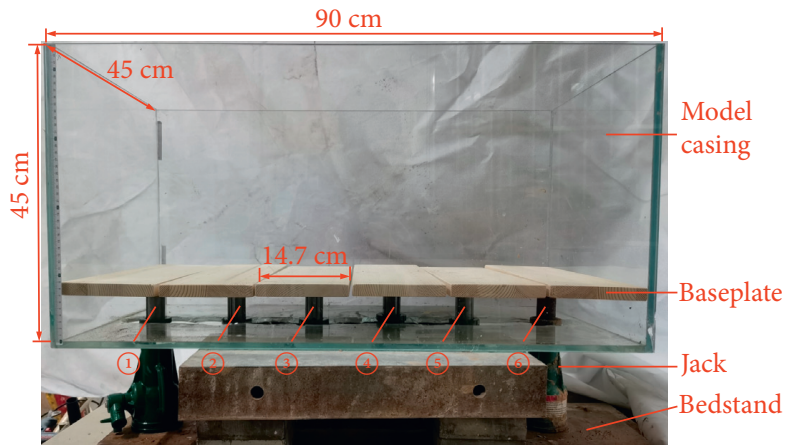

Figure 2: Test system. 
schemes 1 and 2 were $90 \times 45 \times 16 \mathrm{~cm}$ and $90 \times 45 \times 14 \mathrm{~cm}$, respectively. The mining height for both model designs was $4 \mathrm{~m}$. Following a 1:100 experimental ratio, a subsidence spacing of $4 \mathrm{~cm}$ was created under the supporting plate by unloading of the jack.

(2) Adjustment of the experimental system. Prior to carrying out the experiment, the system was adjusted according to the designed scheme. The hydraulic jack was first adjusted in a reasonable position with appropriate horizontal spacing to maintain the designed conditions. The height was then adjusted to allow $4 \mathrm{~cm}$ of space between the supporting plate and bottom of the box. The horizontal spacing of the supporting plate was adjusted to maintain a $3 \mathrm{~mm}$ gap between the two plates as a water channel.

(3) Building the experimental model. The materials used in the models were collected from the undisturbed red soil on-site. The raw materials were placed in the model box, compacted, paved to the designed design height, and left stationary for $24 \mathrm{~h}$. A layer of waterproof material was applied around the inner wall of the box to prevent downward water flow. Water was slowly injected into the box through the external water injection pipeline. The designed water height of both experiment groups was $4.5 \mathrm{~cm}$, and the water was kept at rest for $16 \mathrm{~h}$. The height of the upper water body was held fixed to measure the initial permeability coefficient prior to mining. The experimental model is shown in Figure 3.

(4) Unload the hydraulic jack. The hydraulic jack was unloaded to simulate the coal seam mining process. Starting from jack 1 (Figure 2), the valve was opened to allow slow unloading until reaching $4 \mathrm{~cm}$ of the supporting plate to make complete contact with the bottom of the box. The conditions were then maintained for $8 \mathrm{~h}$ in a static state. The water penetration test was performed and the permeability was recorded. Jacks 2-6 were unloaded in turn and held for $8 \mathrm{~h}$ in a static state, and tests were performed to measure the $k_{2}-k_{6}$ permeability coefficients.

3.3. Test Analysis. After the water had fully permeated into the soil layer, the permeability coefficients of the experimental schemes 1 and 2 were determined to be $k_{10}=1.45 \times 10^{-6} \mathrm{~cm} / \mathrm{s}$ and $k_{20}=1.414 \times 10^{-6} \mathrm{~cm} / \mathrm{s}$, respectively. The results show that the water permeated very slowly into the cohesive red soil layer and that the soil permeability coefficient was small for both schemes under static conditions. This indicates the good water insulation performance of the cohesive red soil layer. Experimental scheme 1 was taken as an example to further explain the variation characteristics of the cohesive soil layer and upper water during different unloading stages, as shown in Figure 4.

Figure 4(a) shows that when jacks 1 and 2 were unloaded, the supporting plate at the top of the soil showed notable sinking and the water level significantly increased.

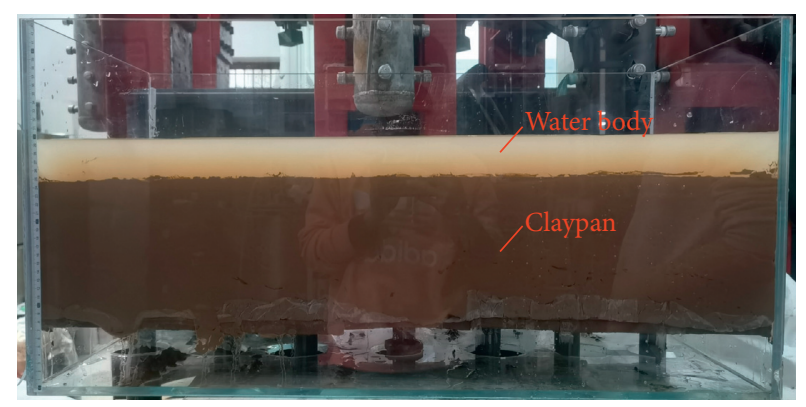

FIGURE 3: Experimental model.

Supporting plates 2 and 3 above the vertical soil displacement responded poorly and the two plate transition positions above the soil show notably opened cracks, which can be observed in the experimental flow along the open fracture that infiltrated the soil and outflow through the gap in the plate.

When four jacks were unloaded, the soil above supporting plates 1-4 subsided significantly and the extent of vertical subsidence of the top interface was essentially equal. The opened cracks generated in Figure 4(a) had healed and decreased in size. However, notable vertical displacement differences occurred in the soil above the fourth and fifth supporting plates along with the formation of vertical cracks. The developed cracks were large in both width and depth. Water rapidly flowed into the soil body along the cracks and ultimately through the void between the supporting plates.

When six jacks were completely uninstalled, the soil displacement was equal throughout. The open cracks in Figure 4(b) decreased and closed owing to the balanced stabilization. Coupled with the expansion characteristics under the influence of water, serious cracks ultimately formed during the development of the automatic bridges, which evolved into multiple small cracks, as shown in Figure 4(c). The features of the mining-induced fractures can be observed from the clayey soil layer at the top. Figure 5 is analyzed to constrain the clay aquiclude characteristics when jacks 3, 4, and 6 were unloaded to monitor the jack fracture development characteristics.

Figure 5 clearly shows a substantial decrease of the width of the new cracks that formed in the center upon unloading but that new cracks formed and continued to form below the bridging feature. This demonstrates that the cracks initially opened and then evolved into having bridge characteristics. The water insulation properties of the clay waterproof layer also accordingly changed during the experiment. In the initial static state prior to mining damage, the water permeability of the soil layer was good and the water inflow between the supporting plates at the bottom was very weak. During the mining disturbance, a certain number of cracks appeared in the soil layer along which water quickly penetrated. In the experiment, significantly more water flowed between the two supporting plates during the mining disturbance than prior to the mining disturbance. This indicates a weakened water permeability of the cohesive soil layer and enhancement of the permeability during unloading. However, after deformation and stabilization of the soil layer, the 


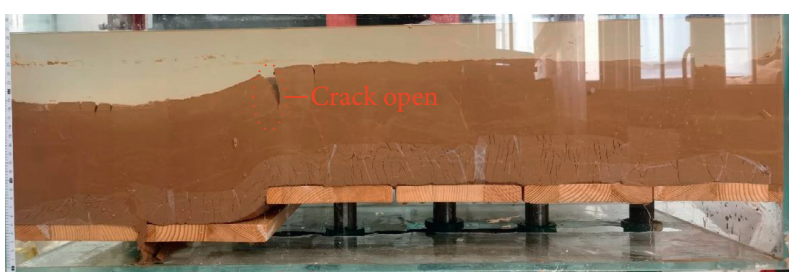

(a)

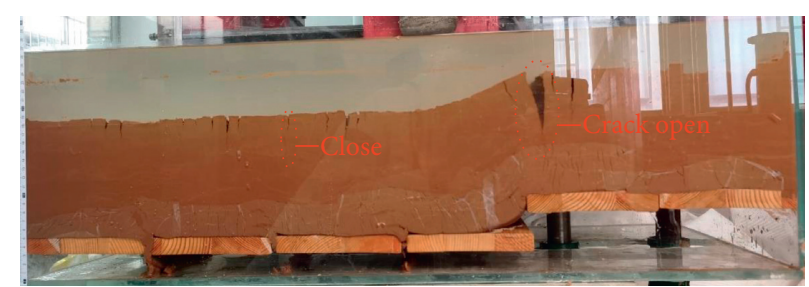

(b)

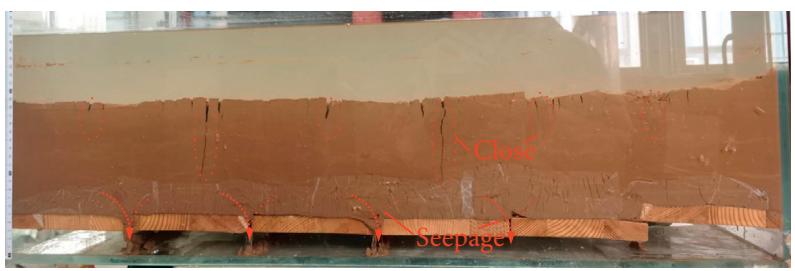

(c)

FIgURE 4: Metabolic water isolation characteristics in different unloading stages. Photograph of (a) two, (b) four, and (c) six unloaded jacks.
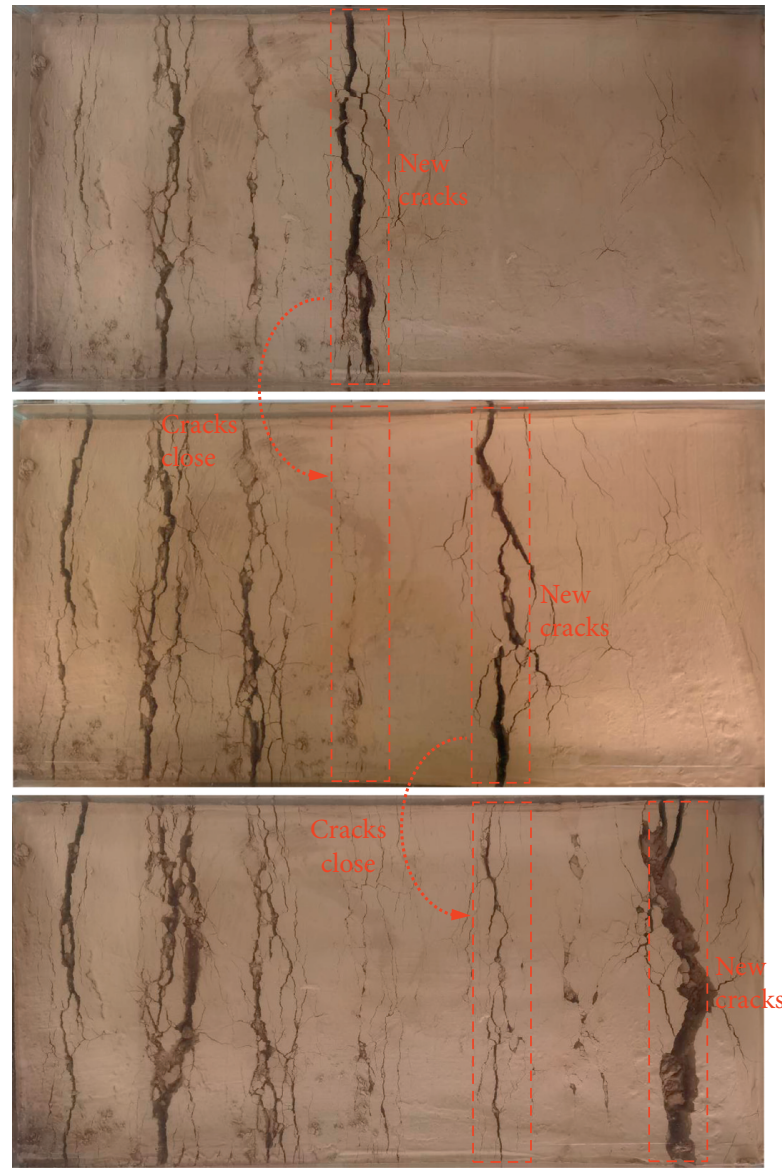

FIGURE 5: Metabolic characteristics of the top clay watertight layer during unloading.

cracks in the soil layer healed and the water penetration into the soil layer slowed, thus also reducing the water inflow between the bottom supporting plates. This indicates that the water insulation of the cohesive soil layer can be restored to a certain extent after mining-induced deformation and stabilization.
3.4. Variation of the Soil Permeability Coefficient. As shown in Figure 6, the permeability coefficient values of the two test groups were extremely small during the original static state prior to the mining disturbance. The increased amount of unloading continuously enhanced the extent of the mining disturbance in the clay soil and altered its mechanical properties, as reflected by an increased permeability coefficient with further mining disturbance. After unloading, the permeability coefficients of experimental groups 1 and 2 reached maximum values of $3.27 \times 10^{-6}$ and $2.82 \times 10^{-6} \mathrm{~cm} / \mathrm{s}$, respectively. Upon further unloading, the mining-induced fractures in the cohesive soil layer gradually decreased or even closed, leading to a gradual decrease of the permeability coefficient to $2.65 \times 10^{-6}$ and $2.02 \times 10^{-6} \mathrm{~cm} / \mathrm{s}$, respectively, once the deformation stabilized. However, the postmining permeability coefficient was still greater than the original value in the undisturbed state owing to the soil expansion. The crack widths and depths strongly decreased but did not completely heal. The soil infiltration path was shortened during deformation; thus the soil stability did not fully recover its waterproof ability. The results of the two different experimental schemes show a similar pattern but the increase of the soil permeability coefficient was less extreme for scheme 2 (16 $\mathrm{cm}$ thick soil layer) and decreased to a lower value after the peak than in scheme $1(14 \mathrm{~cm}$ thick soil layer $)$. This demonstrates that the overall deformation damage is more severe for thinner soil layers and the permeability enhancement is more extreme.

\section{Recovery Mechanism Analysis}

The experimental results show that water mining disturbances initially alter the properties of the water insulation clay layer but then somewhat restore its waterproof ability. Soil volume expansion is stronger under the influence of water expansion, which causes the original mining cracks to automatically heal and ultimately restores the soil water capacity. 


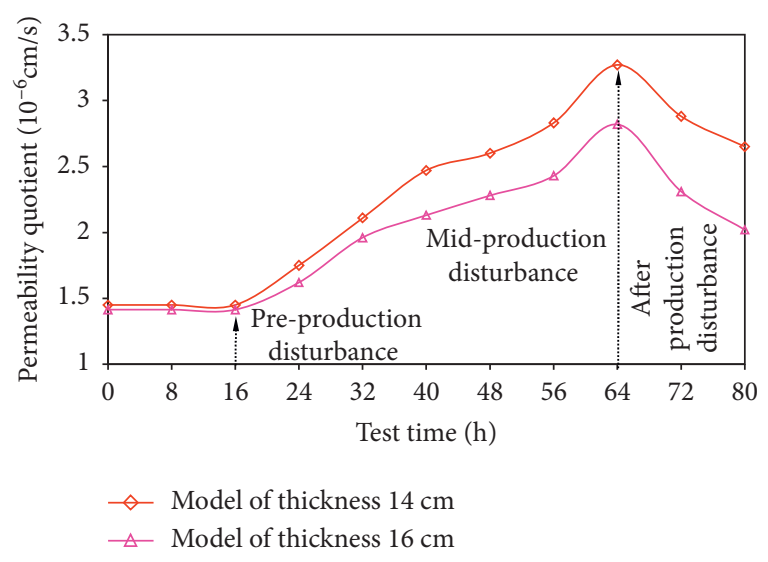

FIgURE 6: Variation of the soil permeability coefficient during different mining stages.

Further analysis is required to constrain the viscosity changes during mining when the mining-induced fissures open and close. The sticky soil mining water recovery process and associated mechanical isolation mechanism can thus be studied by analyzing the fracture evolution process.

4.1. Theoretical Hypothesis of Clay Layer Spatial Movement. Soil has reduced mobility under coal extraction conditions, which simultaneously subjects the lower and upper parts of the soil to tension and squeezing, respectively. Vertical shear stress is also produced under the action of gravity and loading. The combination of tension and shear stress produces vertical mining-induced fractures along the horizontal direction that develop from the bottom up. The water expansion characteristics of the viscous soil cause the mining cracks in the soil to gradually bridge, while the soil deformation stability remains essentially unchanged.

The visible mining-induced opening/closing of fissures is closely related to soil movement. The variation of mininginduced fractures can be expressed by the spatial movement of the clay soil. The following model assumption is taken to study the viscous soil layer cracks and their mining mechanics mechanism. Soils that are affected by mining disturbances generate mining-induced fissures owing to water swelling of the clay layer, and mining cracks form during the process by which the soil moves to automatically bridge the cracks. Soil stability upon fracture closure is thus related to the soil movement.

Stochastic medium theory has become the most widely used in recent years to study the movement of subsided strata [33]. In the random medium theory calculation method, the spatial movement of clayey soil is analyzed using an infinitesimal element within a soil $P(X, Y, Z)$ and its trajectory can be decomposed into horizontal and vertical directions, which are influenced by the dominant mining disturbance part of the soil in the vertical direction to approximate the degree of soil spatial movement.

The calculation area selected here corresponds to the fluid-structure coupling mining water isolation experimental model in Figure 3. The theoretical calculation model follows the experimental model scale of $1: 100$. The calculation model is $90 \mathrm{~m}$ long with a vertical height of $16 \mathrm{~m}$. Working from left to right, each propulsion step from $1 \mathrm{~m}$ is a downward movement of $4 \mathrm{~m}$; thus, the fixed horizontal border soil can only move up and down. The selected theoretical calculation model is shown in Figure 7.

According to the theoretical hypothesis model, the generation of vertical displacement of an element body indicates that it is moving and that a certain mining-induced fracture will occur in this region. However, when the vertical displacement is reduced to zero, the element body stops moving and the fracture in this region automatically closes. The calculation of the vertical displacement of the element body is solved numerically using the Gauss-Legendre method and the model dimensional parameters are substituted into the formula. The superposition calculation is carried out using MATLAB software.

4.2. Evolution Process of Mining-Induced Fracture OpeningHealing. The calculated evolution process of the mininginduced fractures during different stages of working face advancement is shown in Figure 8 based on the analysis of the relationship between the vertical subsidence displacement of the clay soil and mining-induced fractures.

The soil layer near the working face is most strongly affected when the working face advances to $15 \mathrm{~m}$, during which the soil layer is in the most active movement and deformation stage, and the vertical subsidence displacement strongly varies. Mining disturbance causes fractures to develop vertically in this area. When the working face advances to $30 \mathrm{~m}$, the same soil range is affected and new cracks are generated. However, the rear part of the soil simultaneously gradually stabilizes and the vertical subsidence displacement essentially returns to the initial value owing to the viscous soil dilatability and crack bridging that occurs when the working face advances to $15 \mathrm{~m}$. Similarly, when the working face advances to $45 \mathrm{~m}$, new fractures occur in the soil layer near the working face that are severely affected by the mining disturbance. The generated fractures also undergo automatic healing at this point. The formed cracks thus ultimately close upon working face advancement and the mining-induced water isolation of the soil layer is weakened. After the movement and deformation are stabilized, the original cracks in the soil layer are automatically healed and the overall waterproof property of the soil layer is restored to a certain extent.

\section{Water Conservation Mining in Mud-Capped Coal Seams}

According to the literature [34], waterproof and protective coal pillars must be set up to ensure that no additional increase of mine water inflow occurs during the mining process. The coal pillar size should be greater than the sum of the maximum height of the overburden water-conducting fracture zone and protective layer thickness to avoid allowing the fracture zone to spread to water body. Experimental studies have shown that the clay layer will change after the first fracture opening process. Upon bridge repair, 


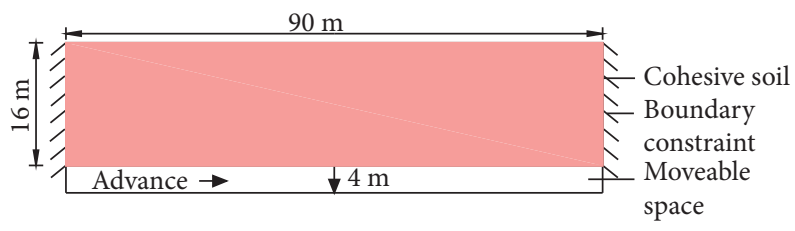

FIgURE 7: Theoretical model of the clay spatial motion.
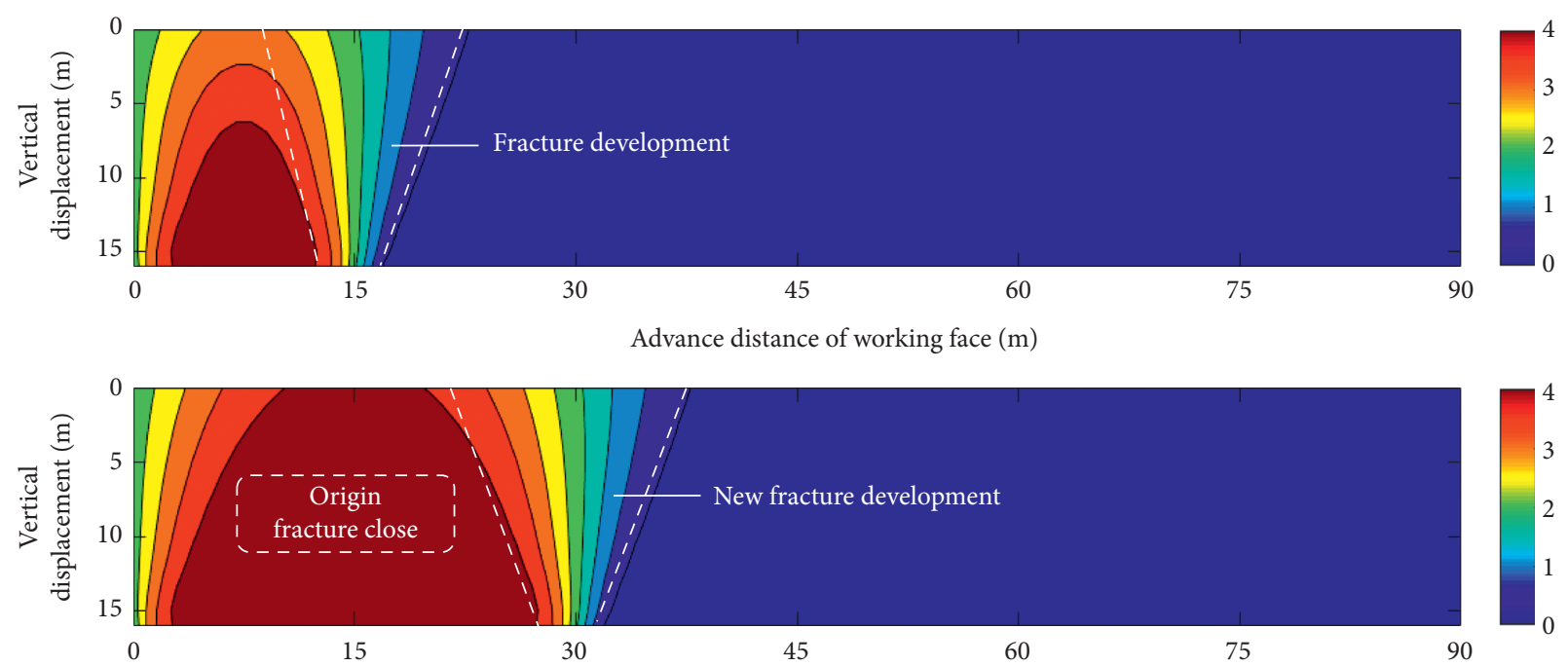

Advance distance of working face (m)

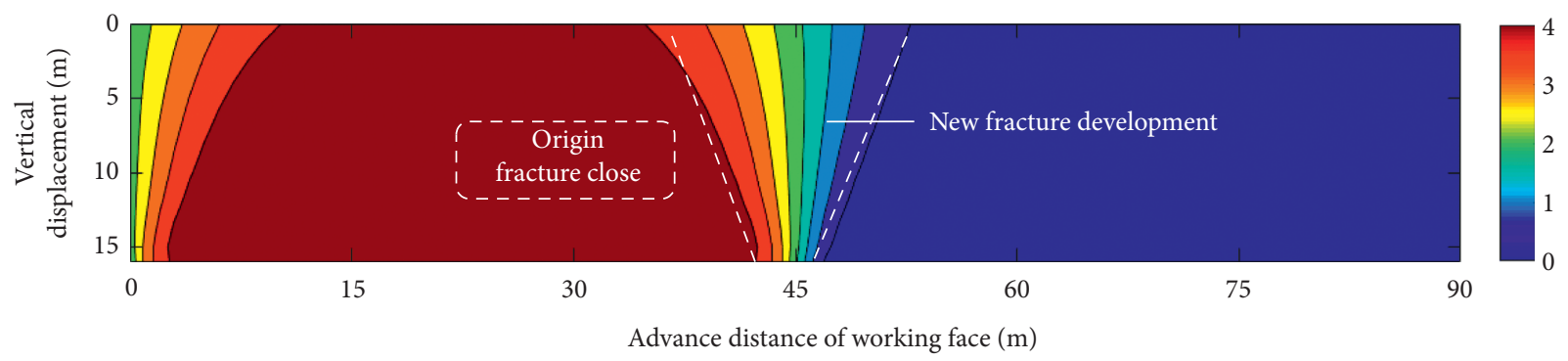

FIGURE 8: Mining fracture generation-bridging evolution process during working face mining.

the clay layer also shows good waterproof performance by forming a mud-covered bridge belt. The bridge limits the height of further water crack development and can also serve as a waterproof coating.

The coal seam thickness is used to calculate the protective coal pillar size using the traditional method, but the accuracy is limited and partially conservative owing to the low recovery rate and high waste of coal resources. The effect of the mud-cap damage rule in overlying rock mining should therefore be applied using the traditional method to optimize the coal pillar size and determine suitable new methods for designing mud-cap waterproof coal pillars.

\subsection{Optimal Design of WaterproofCoal Pillar in Mud-Covered} Coal Seam. Using the conventional method to calculate a nearly mud-covered type of coal pillar can be problematic owing to damage changes of the overburden rock. The result is influenced by the viscous soil inhibition rock, which leads to a strongly reduced height of the developed cracks and large waterproof coating thickness. The mud coal pillar design must thus account for the development of the fracture zone height and protective layer thickness.

Mud-capped rock leads to crack heights that depend on their own unique destruction behavior (Figure 9) and water loss. Borehole drilling, computed tomography (CT) scans, digital imaging physics of similar material simulations, direct or indirect testing, and a large amount of field measured data show that the mud-cap effect typically leads to the development of a fracture zone height that is 0.5-0.7 times the thickness of the fully developed bedrock layer. A reasonable thickness of the protective layer should therefore account for the water insulation of the mud cover sealing zone that forms after the automatic sealing of the mininginduced cracks on top of the fracture zone. There is no need to leave a protective layer if the water insulation of the mud cover sealing zone is good and can exert an adequate water insulation effect. However, if the water insulation of the mud 


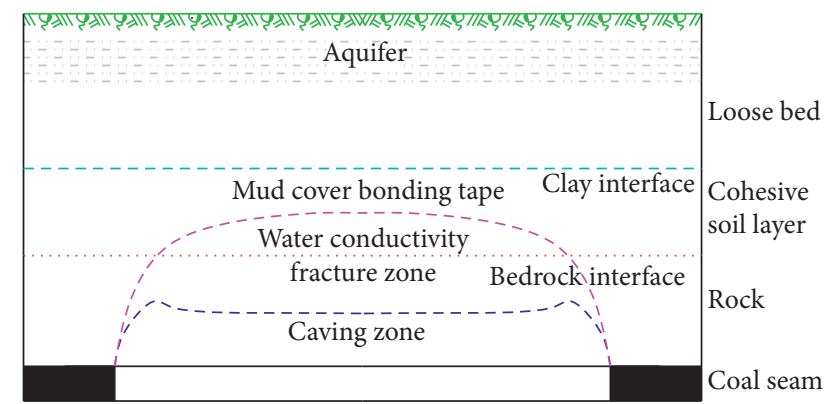

FIGURE 9: Structural characteristics of the overlying strata under the effect of a mud cap.

cover bonding zone is weak, a certain primary cohesive soil layer thickness should be left on the upper part of the bonding zone as a supplement. Because the water insulation properties of the primary cohesive soil layer are strong, the supplementary thickness left can also be appropriately reduced by $0-3$ times the mining height. According to the water insulation effect of the mud-capped bonding zone, it is comprehensively determined that the protective layer thickness should be 0-3 times the mining thickness. The actual water insulation effect of the mud-capped bonding zone can be determined by mining water insulation tests of the reclaimed rock mass.

However, the key to the size design of a waterproof protective coal pillar when mining a mud-capped coal seam is to accurately assess whether or not the overburden failure produces a mud-cap effect. If the overburden failure does not produce a mud-cap effect, the calculation can be carried out using the traditional waterproof coal pillar formula. If the overlying rock failure causes the mud-cap effect, it is necessary to optimize the coal pillar size determination method. The formation of a mud-cap effect owing to overburden failure is closely related to the rock structure, hydrogeological characteristics, as well as the physical mechanics and hydrologic characteristics of the rock and soil mass. The following three conditions for generating the mud-cap effect by overburden failure are summarized according to a large amount of field data measured in the early mining stage.

(1) The minerals of the mud cap have certain crack resistance, expansion, and water-resistance properties.

(2) The bedrock pillar thickness is less than or equal to 8-10 times the mining height.

(3) The mud-cap thickness is more than or equal to 5-9 times the mining height.

A method to optimize the size and design of the waterproof protective coal pillar for the mining of mud-capped coal seams is shown in Figure 10 and the specific steps are listed as follows.

(1) The lithology and thickness of each layer above the coal seam roof are determined according to surface exploration drilling and a stratum structure profile is drawn. The mineral composition of the rock and soil body is also determined, as well as the basic physical mechanics, geoengineering, and hydrological properties.

(2) The production of a mud-cap effect owing to overburden strata failure is assessed according to the occurrence conditions of the overburden mud-cap effect combined with the mining parameters of the working face, strata structure, and hydrogeological characteristics.

(3) If the damaged strata can produce a mud cover effect, the section water loss can be assessed by boring, drilling, drilling a CT scan, digital imaging physics of similar material simulations, and direct or indirect methods. The mud-cap damage rule of overlying rock can be detected to assess the development of the crack height.

(4) The position and thickness of the overburden mudcap bonding zone are analyzed and the mining water isolation is tested through experiments to determine the reasonable protective layer thickness.

(5) If the sum of the developed water conduction fracture zone height and protective layer thickness does not exceed the distance between the coal seam and aquifer, safe mining and water conservation mining can be operated without the threat of roof water damage. If the sum exceeds this value, the safety requirements cannot be met. The mining scheme design of limited thickness mining, wide strip mining, filling mining, and room and pillar mining and the technical measures for water prevention and control and water conservation are given.

\subsection{Determination of the Waterproof Pillar Size in the Hao} Jialiang Coal Mine. The size of the waterproof protective coal pillar for a mud-covered coal seam is optimized taking the 2301 working face within coal seam no. 3 of the Hao Jialiang coal mine as an example. The average extraction length is $7 \mathrm{~m}$, the oriented face is $220 \mathrm{~m}$ thick and $1700-\mathrm{m}$ long, and the large mining height has broken owing to fully mechanized mining. The coal seam is buried to a depth of $110-160 \mathrm{~m}$. The bedrock thickness is $12-45 \mathrm{~m}$ and deposited as a 38.4-62.4 $\mathrm{m}$ thick layer above the Neogene bedrock of JingLe red clay, Quaternary Lishi group, and the Quaternary Sarah WuSu aquitard, which is a wind-blown sand layer. The Holocene roof is a typical combination of thick "BoJi"-type soil strata lithology.

The traditional linear regression formula projects a vertical height of the waterproof protection coal pillar of $100.37-104.45 \mathrm{~m}$. We use the proposed method of mudcapped coal seams to check this value according to [35-37] through drilling, drill loss observations, and digital imaging methods such as physical analog simulations integrated to determine the water flowing through the fracture zone of the 2301 face at a height of $49.3 \mathrm{~m}$. Soil regeneration tests have shown that the sticky soil of the Hao Jialiang coal mine has good water retention properties and the design of a 


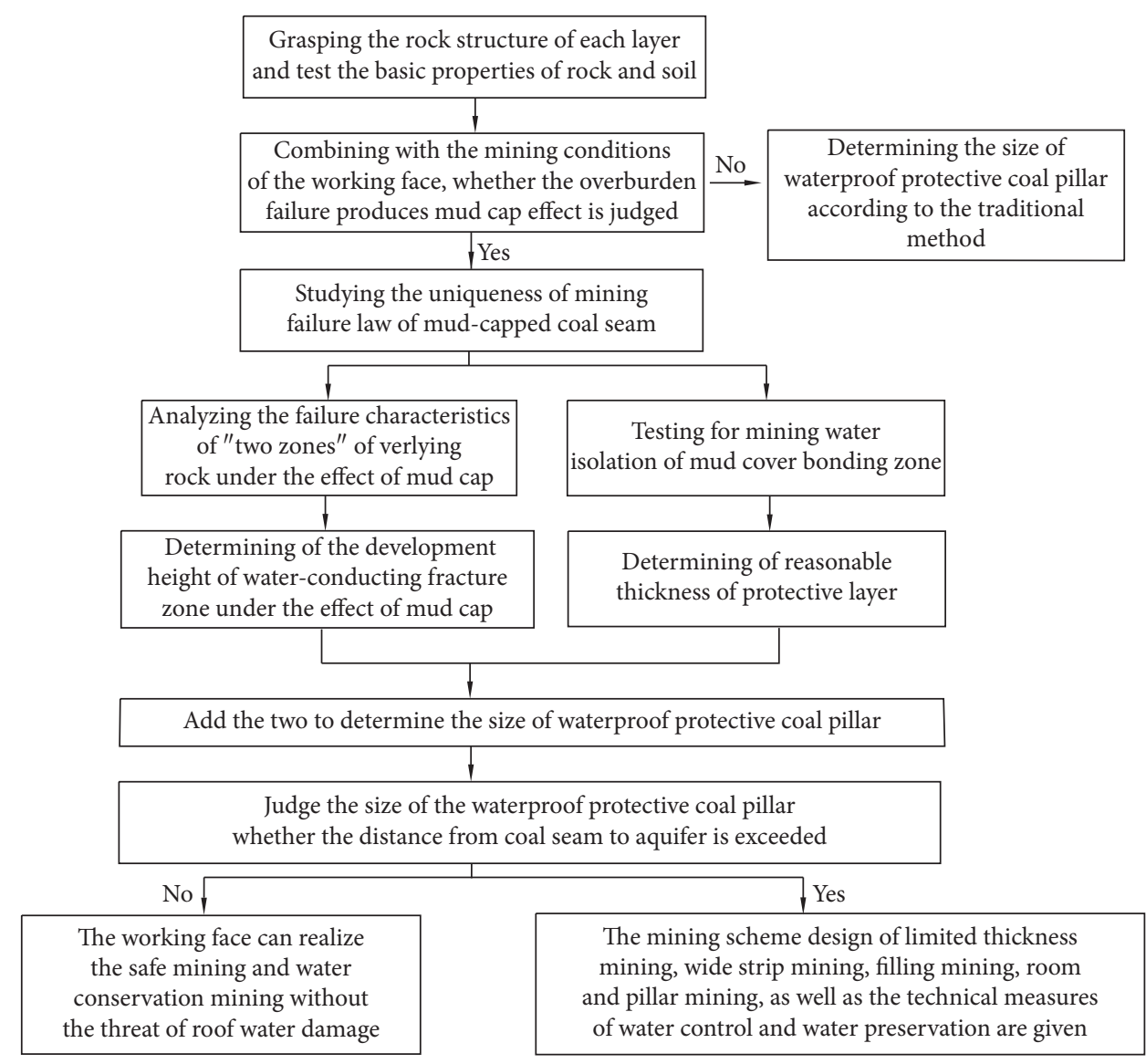

FIGURE 10: Flow chart of the optimized design of waterproof pillar size in mud-capped coal mining.

waterproof protection coal pillar cannot serve as a protective layer. The fractured zone height is thus a minimum waterproof protection coal pillar size, yielding a value of approximately $50 \mathrm{~m}$ for the 2301 working face. The calculated height of the waterproof protective coal pillar is shown in Figure 11 compared with the bedrock section and laterite layers within the working face.

A comparative analysis of Figure 11 shows that the height of the waterproof protective coal pillar calculated using the traditional method will break through the Neogene red soil layer. The pore fracture division of the loess overlying the loose Quaternary rock and Salawusu Formation will thus pose a threat to safe production of the working face. It is therefore evaluated that the total mining height of the 2301 working face should be $7 \mathrm{~m}$ at a time. The optimization design method is used to determine the height of a waterproof protection coal pillar that does not break through the Neogene red soil and Quaternary unconsolidated rock. The coal pillar design is therefore reasonable and meets the requirements of water prevention and control of the working face.

5.3. Evaluation of Water Conservation Mining Effect of a MudCapped Coal Seam. A low-lying area riverbed occurs above the 2301 working face. After mining, the surface of the basin subsided. The subsided basin has a water depth of 1-5 m with a water area of nearly $20,000 \mathrm{~m}^{2}$ and volume of

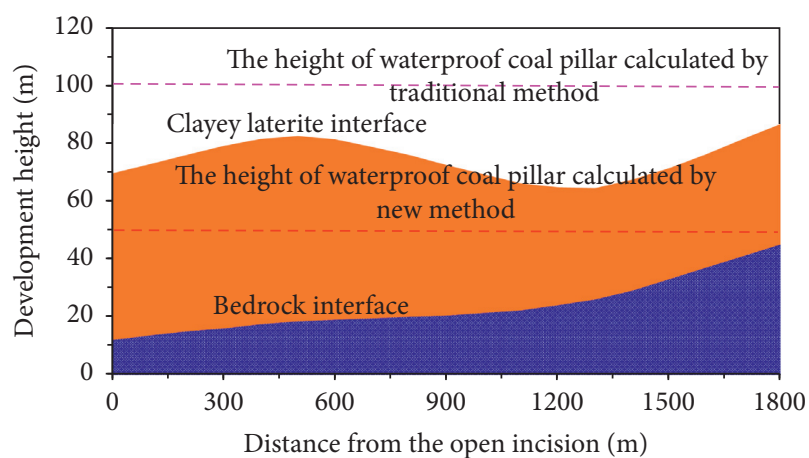

Figure 11: Comparison of calculated waterproof protective coal pillar sizes.

$60,000-70,000 \mathrm{~m}^{3}$. Ground fissure and basin water accumulation above the working face are shown in Figure 12. The water depth of the basin was observed synchronously during the mining of the working face. The results show that water depth of the basin changed little after mining.

The water inflow changes during working face mining are shown in Figure 13. The maximum and minimum water inflow values are 70 and $35 \mathrm{~m}^{3} / \mathrm{h}$, respectively. The face directly fills water only for the Mesozoic clastic rock with cranny pore water and confined water and Quaternary unconsolidated rock, but not the surface water through the 

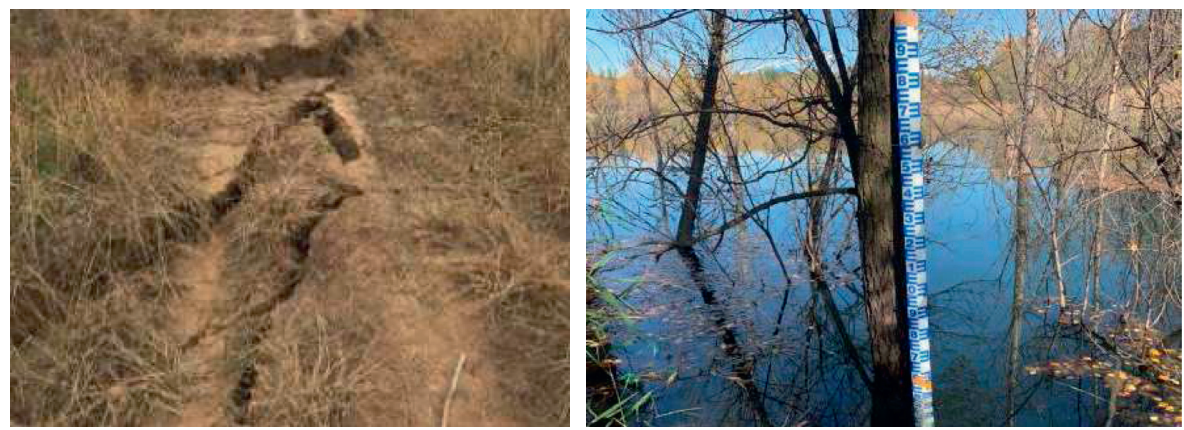

FIGURE 12: Ground fissure and basin water accumulation above the working face.

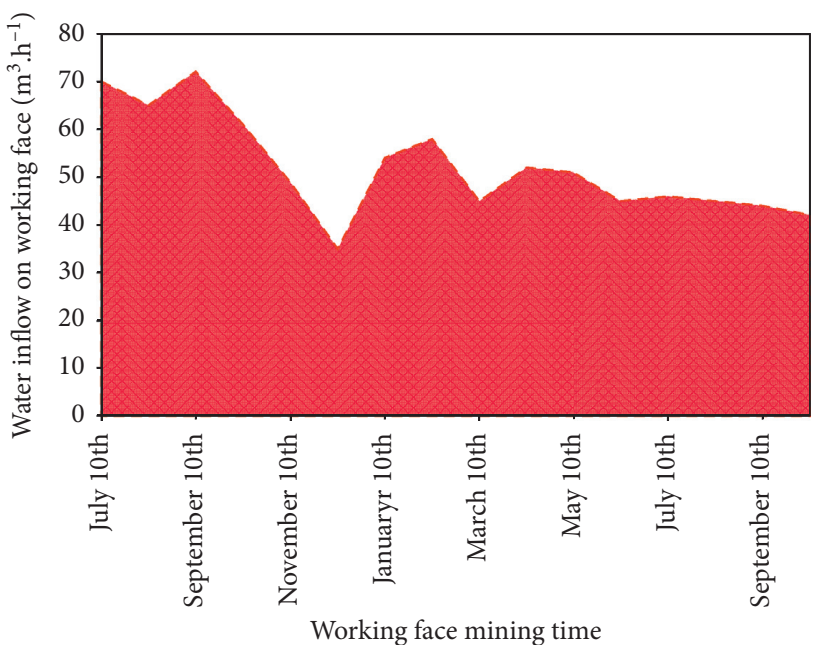

FIGURE 13: Change of water inflow measured during mining of the working face.

water channel into the working face. Special water pumps are also arranged as transport and return air channels for drainage during the mining process. The production practice shows that no seepage accidents occurred in the working face and the water source in the roof aquifer poses no threat to the normal production. This not only ensures safe coal mining under the water body, but also ensures that the fragile ecological environment on the surface remains unaffected, which achieves the purpose of water conservation mining.

\section{Conclusion}

(1) The physical and mechanical property test results of the clay soil in the Yushen mining area show a relatively high clay mineral content of the soil, which is dominated by a Yimeng mixed layer of mostly illite. Compared with sandy soil, the clay soil in this mining area has the basic characteristics of high shear strength, strong expansion, extremely weak water permeability, and good water insulation.

(2) The results of fluid-solid coupling mining water isolation experiments of the clay layer show that mining-induced fractures in the soil layer initially open with increased unloading and then close. The overall water isolation of the soil layer initially weakens and then recovers and the corresponding permeability coefficient of the soil layer initially increases and then decreases. The variation of the mining-induced water insulation characteristics can be measured by the movement of the soil layer. The evolution of the mining-induced fractures is analyzed using stochastic medium theory and the recovery mechanism of the mining-induced water insulation properties in the clay layer is expounded.

(3) The mud-capped strata form a mud-covered bridge belt during mining. The existence of the bridge can reduce the coal layer thick and affect the waterproof protective coal pillar design. This approach is applied to the 2301 working face of the Hao Jialiang coal mine and the optimization design method is verified based on the measured mine water inflow data, which improves the working face mining upper limit.

\section{Data Availability}

The data used to support the findings of this study are available from the corresponding author upon request.

\section{Conflicts of Interest}

The authors declare that they have no conflicts of interest.

\section{Acknowledgments}

This work was supported by "National Natural Science Foundation of China (Grant no. 51704161)" and "Key Research Development and Promotion Special Project of Henan Province (Grant no. 212102210229)" and "Key Research Projects of Higher Education Institutions of Henan Province (Grant no. 21A440014)".

\section{References}

[1] L. Fan, X. Ma, Z. Jiang et al., "Review and thirty years prospect of research on water-preserved coal mining," Coal Science and Technology, vol. 47, no. 7, pp. 1-30, 2019.

[2] L. Fan, "Some scientific issues in water-preserved coal mining," Journal of China Coal Society, vol. 44, no. 3, pp. 667-674, 2019. 
[3] L. Fan and X. Ma, Theory and Practice of Coal Mining with Water Conservation, Science Press, Beijing, China, 2019.

[4] L. Ma, J. Guo, W. Liu, D. Zhang, and Y. Yu, "Water conservation when mining multiple, thick, closely-spaced coal seams: a case study of mining under weishan lake," Mine Water and the Environment, vol. 38, no. 3, pp. 643-657, 2019.

[5] S. Dong, W. Hao, and X. Guo etal, "Characteristics of water hazards in China's coal mines: a review," Mine Water and the Environment, vol. 40, pp. 325-333, 2021.

[6] J. Ju, J. Xu, Q. Li et al., "Progress of water-preserved coal mining under water in China," Coal Science and Technology, vol. 46, no. 1, pp. 12-19, 2018.

[7] B. Wu, J. Peng, M. Xiang et al., "Research of Salawusu formation aquifer is protected by water-conserving mining in Yushenfu minging area," Journal of Mining \& Safety Engineering, vol. 35, no. 5, pp. 984-990, 2018.

[8] J. Chang, W. Li, T. Li et al., "Water migration in arid mining area and thought of "water preserved mining", Journal of Mining \& Safety Engineering, vol. 31, no. 1, pp. 72-77, 2014.

[9] F. Feng, S. Peng, W. Du, Y. He, and S. Chong, "The assessment and evolution of water-conducting rules under the influence of mining-induced stress," Advances in Civil Engineering, vol. 2018, Article ID 5920841, 11 pages, 2018.

[10] Z. Yang, W. Wang, and J. Huang, "Research on buried depth of eco-safety about groundwater table in the blown-sand region of the Northern Shanxi Province," Journal of Northwest Argiculture and Foresty University (Natural Science Edition), vol. 34 , no. 8, pp. 67-74, 2006.

[11] X. Ma, J. Huang, J. Li et al., "Ecology orientated groundwater level threshold in mining area," Journal of China Coal Society, vol. 44, no. 3, pp. 675-680, 2019.

[12] D. Yang, W. Guo, and Y. Tan, "Study on the evolution characteristics of two-zone failure mode of the overburden strata under shallow buried thick seam mining," Advances in Civil Engineering, vol. 2019, Article ID 9874769, 9 pages, 2019.

[13] H. Jing, J. Wu, Q. Yin, and K. Wang, "Deformation and failure characteristics of anchorage structure of surrounding rock in deep roadway," International Journal of Mining Science and Technology, vol. 30, no. 5, pp. 593-604, 2020.

[14] Z. Lu, W. Ju, X. Yin, Z. Sun, F. Zhang, and C. Han, "Mechanical analysis of the failure characteristics of stope floor induced by mining and confined aquifer," Shock and Vibration, vol. 2021, Article ID 9955730, 13 pages, 2021.

[15] Y. Li, J. Bai, W. Yan et al., "Risk early warning evaluation of coal mine water inrush based on complex network and its application," Advances in Civil Engineering, vol. 2021, Article ID 9980948, 13 pages, 2021.

[16] X. Xie, E. Hou, S. Wang et al., "Formation mechanism and the height of the water-conducting fractured zone induced by middle deep coal seam mining in a sandy region: a case study from the xiaobaodang coal mine," Advances in Civil Engineering, vol. 2021, Article ID 6684202, 11 pages, 2021.

[17] X. Ma, S. Wang, Z. Jiang et al., "Prediction on the height of water-flowing fractured zone in southern Shenmu mine," Journal of XI'an University of Science and Technology, vol. 36, no. 5, pp. 664-668, 2016.

[18] Y. Gao, M. Xu, and D. Zhang, "Prediction on the height of water diversion fracture zone in coal mining of Yushen mining area," Shanxi Coalm, vol. 36, no. 6, pp. 47-50, 2017.

[19] W. Li, Q. Wang, S. Liu et al., "Study on grade types of waterpreserved- mining coalmines in ecologically fragile area," Journal of China Coal Society, vol. 44, no. 3, pp. 718-726, 2019.
[20] L. Fan, X. Ma, H. Jiang et al., "Risk evaluation on water in rush and sand inrushin ecologically fragile coal mine," Journal of China Society, vol. 41, no. 3, pp. 531-536, 2016.

[21] L. Wu, H. Bai, C. Yuan, G. Wu, C. Xu, and Y. Du, "A waterrock coupled model for fault water inrush: a case study in xiaochang coal mine, China," Advances in Civil Engineering, vol. 2019, Article ID 9343917, 12 pages, 2019.

[22] S. Dong, Z. Yang, Z. Ji et al., "Study on water-preserved mining technology of burnt rock aquifer beside the large reservoir in Shenfu mining area," Journal of China Coal Society, vol. 44, no. 3, pp. 709-717, 2019.

[23] B. Yu, Study on Mining Induced Water Isolation of clay WaterProof Layer in Shallow Coal seam, Master Thesis, Xi'an University of Science and Technology, Xi'an, China, 2009.

[24] T. Li, W. Li, J. Chang et al., "Permeability features of waterresistant clay layer in northern Shaanxi Province while shallowly buried coal mining," Journal of Mining \& Safety Engineering, vol. 28, no. 3, pp. 127-132, 2011.

[25] Y. Xu, "Design methods of the effective water -resisting thickness for the protective seam of the water barrier in fully -caving mechanized coal mining," Journal of China Coal Society, vol. 30, no. 6, pp. 305-308, 2005.

[26] Y. Zhang, Y. Song, P. Chen et al., "Study on comprehensive water insulated performances of deep jurassic system rock strata," Coal Science and Technology, vol. 42, no. 8, pp. 95-98, 2014.

[27] X. Miao, R. Chen, H. Bai et al., "Fundamental concept sand mechanical analysis of water-resisting key stratain waterpreserved mining," Journal of China Coal Society, vol. 32, no. 6, pp. 561-564, 2007.

[28] L. Ma, D. Zhang, S. Wang et al., "Water-preserved mining with the method named "backfilling while mining"," Journal of China Coal Society, vol. 41, no. 1, pp. 62-69, 2018.

[29] D. Gu, "Theory framework and technological system of coal mine underground reservoir," Journal of China Coal Society, vol. 40, no. 2, pp. 239-246, 2015.

[30] Z. Liu, Z. Fan, and Y. Zhang, "Fracture characteristics of overlying bedrock and clay aquiclude subjected to shallow coal seam mining," Mine Water and the Environment, vol. 38, no. 1, pp. 136-147, 2019.

[31] Z. Liu, Z. Fan, Y. Zhang et al., "Experimental study of resistance to mining influence ability of clay aquiclude," Coal Technology, vol. 36, no. 12, pp. 63-65, 2017.

[32] M. Hu, W. Zhao, Z. Lu, J. Ren, and Y. Miao, "Research on the reasonable width of the waterproof coal pillar during the mining of a shallow coal seam located close to a reservoir," Advances in Civil Engineering, vol. 2019, Article ID 3532784, 14 pages, 2019.

[33] B. Liu, J. Zhang, and G. Liao, The Application of Stochastic Medium Theory in Mining Industry, Hunan Science and Technology Press, Changsha, China, 2004.

[34] State Administration of Coal Industry, Rules for Coal Pillar Retention and Coal Mining in Buildings, Water Bodies, Railways and Main Shafts, China Coal Industry Press, Beijing, China, 2000.

[35] Z. Fan and Z. Liu, "Mud cover effect of mining-induced failure of soft overburden in thick clay strata," Journal of Mining \& Safety Engineering, vol. 37, no. 6, pp. 1196-1204, 2020.

[36] Z. Liu, Study on Mining Failure Law of Overlying Rock in MudCapped Coal Seam and Application of Water Conservation Mining, Doctoral thesis, China Coal Research Institute, Beijing, China, 2020. 
[37] J. Hao, H. Bian, A. Chen, J. Lin, and D. Xu, "Karst water pressure's varying rule and its response to overlying strata movement in coal mine," Advances in Civil Engineering, vol. 2020, Article ID 8848924, 7 pages, 2020. 